\title{
Money Doesn't Buy Happiness ... or Does It? A Reconsideration Based on the Combined Effects of Wealth, Income and Consumption*
}

\author{
Bruce Headey $^{\dagger}$, Ruud Muffels ${ }^{\ddagger}$ and Mark Wooden ${ }^{\dagger}$ \\ ${ }^{\dagger}$ Melbourne Institute of Applied Economic and Social Research, \\ The University of Melbourne \\ ${ }_{\text {†Tilburg University }}^{\ddagger}$
}

Melbourne Institute Working Paper No. 15/04

ISSN 1328-4991 (Print)

ISSN 1447-5863 (Online)

ISBN 0734031572

July 2004

* This paper reports on research being conducted as part of the research program, "The Dynamics of Economic and Social Change: An Analysis of the Household, Income and Labour Dynamics in Australia Survey”. It is supported by an Australian Research Council Discovery Grant (DP0342970). A version of this paper was presented at the German Socio-Economic Panel (GSOEP) Users’ Conference, Berlin, 24-26 June, 2004.

Melbourne Institute of Applied Economic and Social Research The University of Melbourne

Victoria 3010 Australia

Telephone (03) 83442100

Fax (03) 83442111

Email melb-inst@unimelb.edu.au

WWW Address http://www.melbourneinstitute.com 


\begin{abstract}
The accepted view among psychologists and economists alike is that economic well-being has a statistically significant but only weak effect on happiness/subjective well-being (SWB). This view is based almost entirely on weak relationships between household income and SWB. But income is clearly an imperfect measure of economic well-being. Also needed are measures of wealth (net worth) and consumption. Wealth provides economic security as well as income, and consumption expenditure is the most valid measure of current living standards.

The paper uses household economic panel data from five countries - Australia, Britain, Germany, Hungary and the Netherlands - to provide a reconsideration of the impact of economic well-being on happiness. The main conclusion is that happiness is considerably more affected by economic circumstances than previously believed. In all five countries wealth affects life satisfaction more than income. In the countries for which consumption data are available (Britain and Hungary), non-durable consumption expenditures also prove at least as important to happiness as income.

In the latter part of the paper, we undertake longitudinal analyses of the effects of changes in economic well-being on changes in satisfaction levels. The aim is to reassess psychological adaptation theory, which has been invoked to explain very weak and even non-significant relationships between change measures. Results from panel regression fixed effects models indicate that changes in wealth, income and consumption all produce significant, though not large, changes in satisfaction levels.
\end{abstract}




\section{Introduction}

The accepted view in psychology is that objective economic circumstances have only a small though statistically significant effect on happiness (Andrews and Withey, 1976; Argyle, 1987; Campbell, Converse and Rodgers, 1976; Diener et al 1999; Diener and Biswas-Diener, 2002; Headey and Wearing, 1992). This view has sometimes been echoed by economists, usually referring to Easterlin's famous 1974 paper, 'Does economic growth improve the human lot?' However the claim that money, and by extension economic growth, have little effect on happiness is almost entirely based on weak relationships between survey measures of happiness and measures of household income. The single exception appears to be a paper by Mullis (1992), which was based on a sample of 55-69 year old American men, and showed that for this age group income and wealth combined additively to affect scores on a composite index of satisfaction with standard of living, housing, neighbourhood, health, leisure and 'life in general'.

Plainly income is not the only or necessarily the best indicator of material standard of living. Using data from five national household panels, this paper estimates the combined effects of wealth (net worth), disposable income and consumption on measures of overall life satisfaction and also measure of subjective economic well-being. This reconsideration indicates that objective economic circumstances have considerably greater impact on subjective outcomes than previously believed.

The point of including a measure of wealth or net worth as one indicator of household standard of living hardly needs to be laboured. Wealth confers economic security; it enables one to tide over bad times at least for a while. It also enables one to borrow money both to cope with bad times and for investment purposes. Most important, both financial and nonfinancial assets generate real income, a real flow of benefits. This is plainly just as true for the housing one lives in, or fine paintings on the wall, as for shares or savings accounts which generate direct cash income.

Now consumption. In order to assess current living standards it is just as important to measure consumption as income. The reason is that it is clear from household expenditure surveys that a high percentage of households (up to $50 \%$ in some countries; mainly in the bottom half of the income distribution) appear to consume more than they earn. The standard but largely untested explanation rests on the hypothesis that people seek to smooth their 
consumption over time, even though their incomes fluctuate. The reasoning is that that they have some perception of their 'permanent income', or longer term earning capacity. It has been suggested that the finding that consumption inequality generally seems to be lower than income inequality lends indirect support to this hypothesis (Barrett, Crossley and Worswick, 2000; Cutler and Katz, 1992; Slesnick, 1998).

\section{Economic and psychological theory}

Until very recently, the two major social science literatures on happiness and well-being - the economic literature on utility and the psychological literature on SWB - steadfastly ignored each other. Economists, fortified by intensive training, learn never to measure utility directly, but instead to infer it from behavior. An exception to this generalization is a group of Dutch economists who, against the tide, have persisted in asking people about satisfaction with their material well-being (Kapteyn et al., 1988; van Praag et al., 1982, van Praag 1993). Most economists, however, follow Samuelson (1938) in treating behaviours as 'revealed preferences'. Utility is viewed as involving trade-offs between work and leisure. Work is regarded as pain but provides the wherewithal for consumption, while leisure is regarded as pleasure. Individuals are viewed as making different trade-offs, depending on their preferences for consumption and leisure, but essentially a happy person is seen as someone with a full shopping basket and lots of free time. This is a rather hedonistic and perhaps shallow view.

In psychology the study of happiness or subjective well-being (SWB) is a fairly new topic (for reviews see Argyle, 1987; Diener, 1984; Diener et al., 1999; Headey and Wearing, 1992; Kahnemann et al., 1999; Veenhoven, 1984). Psychologists have traditionally followed a medical model, seeing themselves as researchers and therapists dealing with the causes and cures of pathologies, and not taking much interest in what may have been seen as the lightweight topic of happiness. Empirical research on well-being began in the late 1960s and 1970s at the Universities of Chicago (Bradburn, 1969) and Michigan (Andrews and Withey, 1976; Campbell, Converse and Rodgers, 1976). The early studies made two 'discoveries', which are still debated but are accepted by the large majority of researchers. These discoveries, if correct, are of great importance to economists and others focused on economic well-being: 
- Economic variables, notably income, appear to have little effect on happiness. This is part of a more general finding that objective circumstances of all kinds (gender, age, marital status, employment status etc) have quite modest relationships with subjective outcomes. Well-being turns out to be much more strongly related to personality traits, reports of the quality of personal relationships and perceptions of one's family, job, health, etc.

- Adaptation appears to swamp the effects of changes in economic circumstances (and other objective circumstances) on happiness. It is claimed that, even if a person's economic circumstances improve dramatically, he/she will rapidly adapt (habituate) and raise expectations of future circumstances, so that no gain in happiness occurs. One much cited study showed this to be true even of lottery winners (Brickman et al., 1978). This result has led to the conclusion that we are all on a hedonic treadmill; apparent improvements in life situation yield no subjective benefits. Certainly at a societal level it appears to be the case that huge increases in material living standards in the past fifty years have produced no gains in average happiness levels in developed countries (Easterlin, 1995; Diener and Biswas-Diener, 2002), although the same is not true of poorer countries.

In just the last five years or so, economists have begun to take an interest in the psychological literature. A landmark piece, 'What can economists learn from the literature on happiness?' (Frey and Stutzer, 2002) appeared in the Journal of Economic Literature, setting out the case for measuring well-being/utility directly and reviewing recent research on the effects of income, unemployment, inflation and institutions on SWB (see also Oswald, 1997).

An important motivation for the recent interest among economists in psychological theories and results relating to SWB is a concern that the 'revealed preferences' approach may be open to challenge. This approach depends on the assumption that people's preferences for goods and leisure are exogenously determined. If preferences are exogenous and relatively fixed, then it can be inferred that increases in supply will increase utility. However, there is a counter-theory. Duesenberry (1949) proposed that preferences are to a large extent endogenous; that people change their preferences in response to what others have and want ('keeping up with the Joneses' is one symptom). If this is so, then one cannot reasonably infer that more goods and leisure, preferred at time $t$, will necessarily increase utility if acquired at t+1. Easterlin’s (1974) famous paper, referred to earlier, appeared to support Duesenberry’s 
theory by showing that, in so far as income affects happiness at all, it is relative income one's own income relative to others in society - and not absolute gains in income that make a difference. A recent issue of the Journal of Economic Behavior and Organization (July, 2001; see especially Hollaender, pp. 227-49) was devoted to the debate about whether preferences are primarily exogenous or endogenous, and the drastic implications for economics of accepting the latter standpoint (see also Frank, 1985).

Some economists might concede that, while it may be desirable to measure utility directly, it cannot be done in a reasonably valid way. Economists have been brought up to the view that it is impossible to make interpersonal comparisons of utility. Does anyone really believe, they ask, that a person who scores 80 on a survey measure of satisfaction (e.g. with their life-as-awhole, or a bundle of goods and services) can really be said to be more satisfied than someone who scores 70 or 75 ? Psychologists who have developed measures of SWB might reply that, taken absolutely literally, no-one does believe that. But, they might say, do economists literally believe that someone who reports an income of $\$ 80,000$ in a survey or a tax return really has a higher income than someone who reports $\$ 70,000$ or $\$ 75,000$ ? What the psychologists claim is that, in general, the people who score higher on satisfaction scales are more satisfied than people who score lower, and 'in general' is all that is needed for statistical analysis or, one might add, for business and governmental decision-making. Businesses and governments, by and large, make decisions relating to groups of people, not individuals.

The central research question here is: to what extent do 'objective' economic circumstances and changes in economic circumstances - affect subjective outcomes? So the analysis will throughout be based on a clear separation between 'objective' measures of household economic circumstances (and 'objective' controls, such as sex, age, marital status and the like) and 'subjective' measures of overall well-being and satisfaction/dissatisfaction with material circumstances (see Figure 1).

It may be noted that, while the first part of the paper reports on static analyses of the combined effects of wealth, income and consumption on SWB, the latter part explores the effects of change in material well-being on change in SWB. The aim in this latter part of the paper is to contribute to the psychological literature on the dynamics of SWB, and in particular to reassess the view that adaptation swamps any observable satisfaction effects of changes in economic circumstances. 
Figure 1

Economic Well-Being and Subjective Well-Being

\begin{tabular}{|c|c|}
\hline Economic Well-Being & Subjective Well-Being \\
\hline Wealth & Life satisfaction \\
\hline Income & $\begin{array}{l}\text { Standard of living } \\
\text { satisfaction }\end{array}$ \\
\hline Consumbtion & \\
\hline
\end{tabular}

\section{Data and Measures}

\subsection{Five National Household Panels: Australia, Britain, Germany, Hungary and The Netherlands}

The main issue covered in this paper is best addressed with cross-national data. Ideally, such data would come from national household panels which collected annual data on life satisfaction, satisfaction with one's material standard of living, household net worth, household net income and household consumption expenditure. Ideal measures of household net worth would be based on a detailed inventory of each household's non-financial assets (housing, businesses etc), financial assets (shares, bank accounts, accumulated pension rights) and debts. The ideal consumption data would be based on the shopping diary method used in national household expenditure surveys.

It is of course impractical for household panels to collect detailed data each year on wealth and consumption. So far as we know, the only panel which came anywhere near doing so was the Hungarian (Tarki) panel which ran from 1992-1997. As described below, this included a fairly extensive battery of questions on household assets, debts and consumption.

The Australian, British, Dutch and German panels have all measured wealth at least once and contain measures of subjective well-being and household income. The British panel also collects a short list of consumption expenditures (see below). So far as we know, other 
available national household panels lack either measures of subjective well-being, or measures of wealth, or both.

In what follows, we briefly describe the data available in each panel and then discuss the validity of our main measures and also data limitations.

Australia: The HILDA Panel 2001-

The Australian (HILDA) panel began in 2001 with a sample of 7682 households, in which 13969 individuals were interviewed. Everyone aged 15 and over in households was interviewed in person. The standard method of maintaining the representativeness of the panel by interviewing split-offs (e.g., children who leave home to start their own family) is used. Like all the panels described here, HILDA asks detailed questions about labour income, asset income, private transfers and government benefits. Taxes are imputed.

A quite detailed inventory of household wealth was included in the 2002 survey. This included housing, business assets, equity and cash investments, bank accounts, accumulated pension holdings, vehicles and collectibles. Questions relating to debt covered housing debt, credit cards, student debt (HECS) and personal debt. Most questions were answered by one respondent (the household reference person or his/her partner) on behalf of the entire household. All questions asked for an exact monetary value, although for those unable to provide a precise figure for pension assets (a particularly difficult topic), bands were used. About two-thirds of households provided complete wealth data. Some components had to be imputed for the remaining third.

By the standards of previous wealth surveys. the HILDA Survey's estimates of assets were fairly satisfactory. Comparing with results for the household sector provided by the Reserve Bank of Australia (RBA), it appears that net worth was underestimated by just under 10 per cent; previous overseas surveys have typically given results 20 to 30 per cent too low (Juster et al, 1999). However, HILDA seems to have seriously underestimated debts; using the same benchmark debts are about 20 per cent too low. A part explanation for this latter discrepancy may be that ABS gives the total of credit card debt at one point in time, using financial institution records. In HILDA, by contrast, survey respondents (the majority) who reported that they usually paid off all card debt at the end of the month recorded zero current debt. 
The measure of 'happiness' in HILDA was a 0-10 scale on which respondents are asked, “All things considered, how satisfied are you with your life? Only the ends of the scale were labelled such that 0 represented 'totally dissatisfied' and 10 represented 'totally satisfied'. The same scale was used to ask about satisfaction with ‘your financial situation'.

\section{Britain: The BHPS Panel 1991-}

The BHPS began in 1991 with about 10300 respondents from 5500 households. Full interviews are conducted with everyone aged 16 years and over in sampled households. Wealth measures were included in 1995 and 2000. The questions covered housing, financial assets, the value of vehicles and the amount of debt owed. They appear not to have explicitly covered business assets. Questions were asked about contributions to retirement pension, but no attempt has been made here to calculate accumulated holdings. In answering wealth questions, respondents were asked to give exact monetary amounts.

In recent years the BHPS has included several questions on consumption: the amount spent by households on shopping for food per week, the amount spent on meals out per month, the amount spent on leisure per month, housing costs, annual domestic fuel costs and purchases of consumer durables in the last year. The last three measures turned out to be unrelated to measures of SWB. ${ }^{1}$ So the consumption measure used in this paper sums and annualizes three expenditures on non-durables: food and groceries, meals out and leisure. ${ }^{2}$ Together these amount to well over half the annual non-durable expenditure of most households.

The BHPS has, since wave 6 (conducted in 1996), also included questions in a supplementary self-administered questionnaire, about the extent of satisfaction with life overall and with household income (as well as other aspects of life). Both items are scored on a 7-point scale.

1 If included in a measure of overall consumption, both these items actually lower the correlation between consumption and subjective outcomes. These initially surprising results are probably due to the fact that housing expenditure is strongly related to how recently one bought one's dwelling, and fuel expenditure is related to the age of a dwelling, as well as size.

2 Respondents gave their answers to these three questions within 12 expenditure bands (under 10 pounds, 1019, 20-29 etc). In calculating total consumption we assumed expenditure at the mid-point of the band. 
Germany: The GSOEP Panel, 1984-

The GSOEP began in West Germany in 1984 with a sample of 12541 respondents. Every household member 16 and over is interviewed. GSOEP was extended to East Germany in 1990 and has been augmented with several further samples in order to include sufficient immigrants and members of 'policy groups'.

Wealth measures were included in 1988 and then in more detail in 2002. A feature of the 2002 survey was that a special sample of high income - and thus potentially high wealth individuals was added. So the GSOEP, unlike the other panels included here, does not inadequately represent the richest 2 to 3 per cent of households who own at least a quarter of household wealth in all Western countries, and so need to be over-sampled in order to get an accurate picture of wealth holdings.

Unusually, the GSOEP asked about wealth entirely on an individual basis, not a household basis. Respondents were initially asked for exact estimates of the value of their property, financial assets, life insurance, businesses, tangible assets and debts. If an exact estimate could not be provided, a method of unfolding brackets was used. This greatly reduced nonresponse, and yielded approximations of each person's holdings.

The subjective outcomes, life satisfaction and satisfaction with household income, are both measured on a $0-10$ scale.

Hungary: The Tarki Panel, 1992-97

The Tarki panel, designed and administered by Professor Rudolf Andorka and his colleagues at the Economics University, Budapest, ran from 1992-1997. The sample size was initially 8237 respondents. Everyone aged 16 years and over in sampled households was interviewed.

A key feature of Tarki was quite detailed questions about both wealth and consumption, asked each year on the household questionnaire, and thus responded to by one person on behalf of the entire household. The main reason for these inclusions was that Andorka and his colleagues doubted whether income by itself was remotely adequate as a measure of economic well-being in a middle income country with a large rural sector, which was making the transition from communism to democracy and capitalism. 
The consumption battery comprised 11 questions (exact monetary amounts) about typical monthly expenditures, plus four about typical annual expenditures on a range of non-durables plus housing. ${ }^{3}$ This was followed by a final question which asked the household respondent to estimate total household expenditure for a typical month. The wealth and debt questions ran for several pages. They covered real estate including agricultural land, bank accounts and building accounts, shares, vehicle values and debts, and paintings and antiques. Major purchases in the last year were also covered.

The life satisfaction question was again scored on a 0-10 scale, as was a question about satisfaction with 'your standard of living'.

\section{The Netherlands: SEP Panel 1984-}

The Dutch panel began in 1984 with a sample of about 11000 respondents. Everyone aged 16 years and over was interviewed. Until 1990 respondents were interviewed twice a year, but since then annual interviews have been conducted.

Moderately detailed questions about assets and debts are asked each year on the individual rather than the household questionnaire. However, it is clear from the sample means that the questions are not detailed enough, because the means are well below national aggregate figures for the household sector available from the Central Bureau of Statistics.

A question about life satisfaction has been asked only twice - in 1988 and 1991 - and then only on a dichotomous scale. This makes the Dutch question too different from life satisfaction as asked in the other countries, so we decided not to use it. ${ }^{4}$ More usefully, a question about 'How well you are getting along on your household income?' has been included every year. The scale runs from 1 ('with great difficulty) to 6 ('very easily') and results relating to it are given in Table 3.

3 The expenditures covered were utilities, rent/mortgage, clothing, doctors, prescribed medicines, other medicines, transport, cleaning woman, nurse, baby-sitting, food, tuition fees, holidays, charity gifts, and money spent on other households.

4 However, in a trial run, results for the effects of wealth and income on life satisfaction were significant at the 0.001 level, although the size of the effects was small, as would be expected with a dichotomous dependent variable. 
Summary of available measures

1. For four of the five countries we use a single item measure of life satisfaction. For all five we use a single-item measure of satisfaction with something like standard of living (household income, financial situation). The original scales were not all of the same length, so for ease of comparison we have transformed them all to run from 0 to 100. Regression coefficients can thus be interpreted as quasi-percentiles.

2. A measure of household net worth (assets minus debts) has been constructed for each country. ${ }^{5}$ The natural logarithm is used in equations since wealth is highly skewed towards the top end.

3. Measures of household disposable income, available for all five countries, have been equivalised, using the International Experts' Scale; that is, income divided by the square root of household size (Buhmann et al., 1988; Coulter et al., 1992).

4. The consumption measures for Britain and Hungary basically include only nondurables. This is entirely true for Britain. In Hungary housing expenditure was included but the other 14 items were non-durables. Correlational evidence indicated that expenditure on non-durables, but not durables was related to life satisfaction. ${ }^{6}$ The British and Hungarian measures of household consumption have also been equivalised, again using the International Experts’ Scale.

\section{Additional notes on the analysis}

1. All analysis is at the individual level, with individuals within households being attributed the household's total level of wealth, income and consumption.

2. The monetary measures are in the currency of the country concerned and are inflation adjusted.

5 It should be noted that for Britain, Germany and Hungary, the author constructed net worth measures and has not yet had the opportunity to check them with specialists in the three countries.

${ }^{6}$ However, there were weak but significant relationships between durables expenditure and satisfaction with standard of living. 
3. Cross-sectional sample weights have been used for most one-year analyses, and longitudinal weights for multi-year analyses. Weights have not been used for regression equations.

\subsection{Issues of Measurement Validity}

\section{Happiness / subjective well-being}

Clearly, single-item scales are not the best measures of SWB available, but they are very widely used in international surveys and have been found to have acceptable levels of reliability and validity (Diener et al., 1999, pp. 277-278). It appears that, in relation to life satisfaction in particular, human beings can make quick global judgments in survey interviews; judgments which pretty accurately summarise their feelings. The global judgments which individuals make about themselves are corroborated by external validity tests done with partners and friends (Diener et al., 1999). Judgments of life satisfaction prove to be reasonably stable; they have a test-retest reliability of around 0.6 , which is about the same as standard tests of blood pressure.

\section{Wealth and consumption}

Wealth is difficult to measure in surveys and, when attempted, is associated with high item non-response and considerable under-estimates of national wealth, if national accounts, which give aggregate measures, are taken as a benchmark. This last result is partly due to under-reporting and partly because the wealthiest 2 per cent or so, who own a vastly disproportionate share, are nearly always under-represented in surveys (Juster, Smith and Stafford, 1999). An equal probability sample will always be poorly placed to measure wealth, given that it is so concentrated at one end of the distribution.

Nevertheless, it may be feasible to measure wealth in a reasonably valid way in household panels. Juster et al. (1999) demonstrated that the more details one asks for - the more specific components of wealth are itemised - the higher are the average levels of wealth estimated. Higher estimates of wealth, like income, are nearly always more valid. In the Australian HILDA panel, using about ten pages of questions (five in the household questionnaire and five in the individual questionnaire), we appear to have come close to matching the official national aggregate figures for household net worth. In the GSOEP panel, as noted, an effort was made to overcome the problem of under-sampling the very rich, and this appears to have 
paid dividends. As noted earlier, the GSOEP also much reduced non-response by using unfolding brackets for components of wealth for which respondents could not provide exact monetary values. The GSOEP got all wealth questions on to one page for those who could give exact values, but the unfolding brackets added several pages for those requiring them.

Questions about consumption expenditures are rarely asked in household panels and other sample surveys because of the belief that, in order to get a valid picture, it is necessary to follow the 'shopping basket' approach taken in national household expenditure surveys. This requires consumers to keep a diary of their purchases for a week or more. The diary method is obviously impractical for a household panel. A recent paper by Browning et al. (2003) suggested a promising way forward. Using household panel data for Canada and Italy, and matching results to national aggregates, the authors showed that questions about just two consumption items - food eaten at home and meals out - combined with standard demographic variables, enabled one to account for about 60 per cent of the variance in total household non-durable expenditure. In other words these two items can be used to obtain a proxy measure of non-durable expenditure. ${ }^{7}$ A few questions about durables, mainly housing, can complete the picture. We have replicated the Browning et al. approach in Australia and confirm that there also food expenditure can serve as a proxy for total non-durables. ${ }^{8}$

\section{Results}

First, to give an overview, Table 1 shows how much variance is accounted for in life satisfaction and satisfaction with standard of living by (i) household income by itself, then (ii) household income and wealth (net worth) combined, then (iii) household income, wealth and household consumption combined. The reason for presenting results in this sequence is that previous research has focused solely on income. So our approach is to use income results as a baseline, and then see how much more variance is accounted for by wealth and consumption. For Australia, Germany and The Netherlands only income and wealth data are available (not consumption), so we give results for these countries in the second row of the table. Then in the third row we add consumption for the two countries for which it is available, namely

\footnotetext{
7 Five terms relating to the food items enter equations: the log of groceries expenditure and its square, the log of meals out and its square, and the cross-product of the logs.

8 The variance explained was $64.5 \%$.
} 
Britain and Hungary. Results are for the latest year available: Australia 2002, Germany 2002, Netherlands 1997, Britain 2000 and Hungary 1996 ${ }^{9}$. Note that in these preliminary runs we 'pretend' that satisfaction is only affected by household economic circumstances; other variables will be added to the analysis later.

Table 1

\% Variance Accounted for in Life Satisfaction (LS) and Standard of Living Satisfaction (SLS) by Income, Net Worth and Consumption

\begin{tabular}{|c|c|c|c|c|c|c|c|c|c|c|}
\hline & \multicolumn{2}{|c|}{$\begin{array}{c}\text { Australia } \\
2002 \\
(N=1255)\end{array}$} & \multicolumn{2}{|c|}{$\begin{array}{c}\text { Germany } \\
2002 \\
(N=17785)\end{array}$} & \multicolumn{2}{|c|}{$\begin{array}{c}\text { Netherlands } \\
1997 \\
(N=4288)\end{array}$} & \multicolumn{2}{|c|}{$\begin{array}{c}\text { Britain } \\
2000 \\
(N=14439)\end{array}$} & \multicolumn{2}{|c|}{$\begin{array}{c}\text { Hungary } \\
1996 \\
(N=3061)\end{array}$} \\
\hline & $L S$ & SLS & $L S$ & SLS & $L S$ & SLS & $L S$ & SLS & $L S$ & SLS \\
\hline Income by itself & 0.5 & 3.6 & 2.9 & 9.0 & na & 8.4 & 1.3 & 8.2 & 4.2 & 4.1 \\
\hline Income + wealth & 1.7 & 9.2 & 4.2 & 12.1 & na & 15.3 & 2.4 & 10.7 & 4.9 & 5.3 \\
\hline $\begin{array}{l}\text { Income }+ \text { wealth }+ \\
\text { consumption }\end{array}$ & na & na & na & na & na & na & 2.4 & 11.1 & 7.0 & 6.9 \\
\hline
\end{tabular}

Note: All results are significant at the .001 level.

The first row of Table 1 confirms the standard view that income by itself only accounts for very limited variance in life satisfaction, but rather more variance in satisfaction with standard of living. Variance accounted for in life satisfaction ranges from 0.5 per cent in Australia to 4.2 per cent in Hungary. The relatively strong relationship in Hungary could be due to the fact that people there give higher priority to financial concerns, given that it is much the poorest of these five countries. ${ }^{10}$ The weak relationships in Australia and Britain may be due to the higher rates of home ownership in these two countries. It may be that

\footnotetext{
91996 was preferred to 1997 because sample attrition was substantial in the final year of the panel.

${ }^{10}$ Dr Zsolt Speder, a co-investigator in Tarki, confirms that research using the Hungarian panel consistently finds a close relationship between life satisfaction and standard of living satisfaction ( $\mathrm{r} \sim 0.6)$, and consistently finds that economic variables account for as much variance in life satisfaction as in the domain satisfaction.
} 
current income has less bearing on current standards of living in countries where many households have made a long-term investment in housing. ${ }^{11}$

The most striking preliminary results, shown in the middle row of the table, relate to wealth. In all these countries the combination of income and wealth accounts for considerably more variance in both life satisfaction and standard of living satisfaction than income alone. In Australia the variance accounted for in life satisfaction goes up from 0.5 per cent to 1.7per cent; tripling off a very low base! Variance accounted for in satisfaction with 'your financial situation’ rises from 3.6 per cent to 9.2 per cent. In Germany, the Netherlands and Britain too, the variance accounted for in subjective outcomes rises substantially (by at least 25 per cent) for both dependent variables. It is also worth mentioning that, in three of the countries (the exception being Hungary), the Pearson correlation of wealth with life satisfaction was higher than for income (see the Appendix).

Discussion of the impact of consumption is best postponed until later analyses (see Tables 24) in which consumption is entered into equations at the same step as income and wealth, rather than being arbitrarily entered last. What Table 1 appears to show is that addition of this third measure of household economic circumstances accounts for substantial extra variance in Hungary but not Britain.

Clearly, if income, wealth and consumption were very highly inter-correlated, it would be impossible for the latter two to account for much additional variance in satisfaction measures. In fact, the observed inter-correlations in these panels are only moderate. So, taking the countries where all three measures are available, we find a correlation between wealth and income in Hungary in 1996 of 0.26 , and between wealth and consumption also of $0.26 .{ }^{12}$ The correlation between income and consumption was 0.50. In Britain (2000) the equivalent correlations were $0.32,0.29$ and 0.44 . In the countries for which only wealth and income data are available the correlations were: Australia (2002) 0.35, Germany (2002) 0.39 and The Netherlands (1997) 0.27 .

It is worth noting that these inter-correlations would be a bit higher if analysis was confined to households headed by prime age men and women. One reason for the low correlation

\footnotetext{
${ }^{11}$ Admittedly, however, this post hoc explanation fails to address the apparently weaker impact of wealth, as well as income, in Australia and Britain.

${ }^{12}$ Medium-term correlations for Hungary, based on averaging wealth, income and consumption over five years, were considerably higher. The correlations between wealth and income, and between wealth and consumption were about 0.5 , and the correlation of income with consumption was about 0.7 .
} 
between wealth on the one hand, and income and consumption on the other, is that wealth peaks at a later age. Nevertheless, these moderate correlations are almost certainly lowered by measurement error in all three variables. The presence of (putatively) substantial measurement error may in itself be a good reason for including all three measures in surveys, and treating them as multiple indicators of the underlying concept of material standard of living.

\subsection{Life Satisfaction}

Of course the evidence in Table 1 could prove deceptive. Not only were the three measure of household economic circumstances considered in an arbitrary sequence, there were also no 'controls'. In Table 2 we now estimate the combined effects of income, wealth and consumption on life satisfaction, controlling for other 'objective' circumstances. As 'controls' we included a range of 'objective' measures, and excluded 'subjective' measures which would be likely to covary with life satisfaction because some people, due to personality and other omitted factors, are just generally more satisfied than others. ${ }^{13}$ Standard demographic, human capital and labour force variables were included (see below). Also used is a measure of 'bad health' which, for all countries except The Netherlands, is a measure of disability or restriction of daily activities, and not a self-report satisfaction or 'good health' measure. For The Netherlands the only available measure was a self-report 'bad health/good health’ dichotomous variable.

For the key monetary predictor variables in Table 2, we print standardized coefficients (Betas), as well as metric coefficients (bs). The usefulness of the standardized coefficients in this context is that they enable us to make direct if crude comparisons of the 'importance' of wealth, income and consumption as predictors of life satisfaction both within and between countries. Ordinary least squares (OLS) regression is used, ${ }^{14}$ and the data relate to the same years as in Table 1.

\footnotetext{
${ }^{13}$ So the effect of including subjective variables on the RHS might well have been to bias the coefficients of main interest due to covariation between the subjective variables, omitted variables like personality traits and the dependent variable of life satisfaction.

${ }^{14}$ The dependent variable is really only an ordinal scale, so strictly speaking an ordinal scale technique like ordered probit analysis would be more appropriate. However, like many researchers before us, starting with Andrews and Withey (1976), we found that OLS and ordinal scale results were substantively little different, and OLS has the advantages of familiarity and ease of interpretation.
} 
Table 2

Impact of Wealth, Income and Consumption on Life Satisfaction (0-100):

\section{OLS Regressions}

\begin{tabular}{|c|c|c|c|c|c|}
\hline \multirow[t]{2}{*}{ Explanatory variables } & Australia & Britain & Germany & Hungary & Netherlands \\
\hline & Beta & Beta & Beta & Beta & Beta \\
\hline $\begin{array}{l}\text { Equivalised } \\
\text { income } / 1000\end{array}$ & $.04 .05^{* * *}$ & $.17 .06^{* * *}$ & $.01 .08^{* * *}$ & $.04 .06 * * *$ & $.03 *$ \\
\hline Net worth (ln) & $.65 .08 * * *$ & $.53 .08 * * *$ & $.05 .12 * * *$ & $.32 .06 * * *$ & $.54 \quad .07 * * *$ \\
\hline $\begin{array}{l}\text { Equivalised } \\
\text { consumption /1000 }\end{array}$ & na & $.13 .01^{\mathrm{ns}}$ & na & $.19 .13^{* * *}$ & na \\
\hline $\operatorname{Sex}(f=1, m=0)$ & $.70 * *$ & $.62^{\mathrm{ns}}$ & $.03^{\mathrm{ns}}$ & $.96^{\mathrm{ns}}$ & $2.27 * *$ \\
\hline Age & $-.74 * * *$ & $-.91 * * *$ & $-.06 * * *$ & $-1.52 * * *$ & $-.87 * * *$ \\
\hline $\mathrm{Age}^{2} / 10$ & $.09 * * *$ & $.11^{* * *}$ & $.01 * * *$ & $.15^{* * *}$ & $.10^{* * *}$ \\
\hline Partnered (1-0) & $4.66 * * *$ & $6.60 * * *$ & $.29 * * *$ & $8.46^{* * *}$ & $6.71 * * *$ \\
\hline Education (years) & $-.52 * * *$ & $-.39 * * *$ & $.02 *$ & $1.26 * * *$ & $.09^{\mathrm{ns}}$ \\
\hline Working (1-0) & $-.17^{\mathrm{ns}}$ & $.36^{\mathrm{ns}}$ & $-.00^{\mathrm{ns}}$ & $-1.00^{\mathrm{ns}}$ & $2.58 * *$ \\
\hline Unemployed (1-0) & $-2.81 * * *$ & $-4.72 * * *$ & $-.92 * * *$ & $-9.89 * * *$ & $-12.06^{* * *}$ \\
\hline Bad health (1-0) & $-5.89 * * *$ & $-12.26 * * *$ & $-.02 * * *$ & $-1.05 * *$ & $-13.72 * * *$ \\
\hline Constant & $87.52 * * *$ & $81.73 * * *$ & $7.50 * * *$ & $62.65 * * *$ & $101.27 * * *$ \\
\hline $\mathrm{R}^{2}$ & $8.4 \%$ & $10.2 \%$ & $11.0 \%$ & $14.1 \%$ & $5.4 \%$ \\
\hline $\mathrm{N}$ & 11755 & 14101 & 9431 & 3055 & 5280 \\
\hline
\end{tabular}

Notes:

1. $* * *$ significant at 0.001 level; ** significant at 0.01 ; *significant at 0.05 ; ns $=$ not significant.

2. Reference variable for employment status: 'not in the labour force'.

3. Equivalised incomes and consumption were divided by 1000 for all countries except Hungary, where the division was by 10000 . 
The evidence in Table 2 quite clearly confirms that wealth is at least as important as income in predicting life satisfaction. The standardized coefficient (Beta) for wealth is in fact a little higher than for income in all countries except Hungary, where it is the same. In all countries wealth and income are both significant predictors at the 0.001 level.

The results for the two countries where we have consumption measures are sharply different. In Hungary consumption is a stronger predictor of life satisfaction than either wealth or income, while in Britain it is not significant even at the 0.05 level. Plainly consumption is better measured in Hungary (15 items rather than 3), but it is not possible to assess whether there is a genuine inter-country difference here, or merely an apparent difference due to measurement error.

Another way of assessing the impact of economic circumstances on life satisfaction is to imagine people moving up or down the economic ladder by (say) 50 percentiles and calculating the predicted effects on their life satisfaction. Changes of this magnitude over five or ten years are not unusual, as users of household economic panel data well know (e.g. Goodin, Headey, Muffels and Dirven, 1999). Here we do an exercise of this kind for Hungary and Britain; the two countries for which consumption data are available, along with wealth and income data. In Hungary a person who moved from the $25^{\text {th }}$ percentile to the $75^{\text {th }}$ percentile of wealth, income and consumption would be predicted to gain 4.6 percentiles on the (0-100) life satisfaction scale. This would be 3.1 per cent due to a gain in consumption, 0.9 per cent due to gain in income and 0.6 per cent due to gain in wealth. (These estimated effects are of course net of the other variables on the RHS). In Britain the picture would be different. There a person who made the same advance in his/her economic situation would gain 3.4 percentiles in life satisfaction, but wealth would make the most difference -1.6 per cent compared with 1.4 per cent due to income and a statistically non-significant 0.3 per cent due to consumption.

These gains in life satisfaction may seem quite modest, and as we shall see, gains in satisfaction with standard of living are considerably greater. To provide some yardsticks, note that the gain in Hungary of 4.6 quasi-percentiles due to these putative changes in economic circumstances compares with a gain of 8.5 percentiles that the Hungarian equation predicts would result from partnering/marrying, and a gain of 8.9 percentiles that would come from getting a job after previously being unemployed. In Britain the putative gain of 3.4 quasipercentiles in life satisfaction due to economic advancement compares with a gain of 6.6 percentiles due to partnering, and 2.6 percentiles due to getting a job. So in both countries big 
economic gains do less for happiness than getting married. However in Britain, although not Hungary, they provide a bigger boost to happiness than finding employment.

The variance accounted for by the three household economics measures, in combination with standard demographic, human capital, labour force variables and 'bad health', ranged from 8.4 per cent for Australia to 14.1 per cent for Hungary. Clearly, on this reading, economic circumstances make a far from trivial contribution to life satisfaction, and clearly their impact is stronger than previous research has concluded.

Dogs which did not bark - population sub-groups and alternative specifications

Separate analyses were run for men and women, and for households headed by people in different age groups. Results were not substantially different from those given above. We also tried alternative non-linear specifications. It seemed a reasonable hypothesis that poor people - say the least well-off decile or quintile in terms of the three indicators of material circumstances - would score considerably lower on life satisfaction than the quantiles above them. In fact, no non-linearity was detected. Another hypothesis, based on the concept of diminishing marginal utility, was that life satisfaction would increase by diminishing increments the further up the distribution of material circumstances one went. This hypothesis, too, proved false. However, in interpreting this result we do not infer that the textbook viewpoint on the diminishing marginal utility of income - a view often invoked to justify progressive taxation - is incorrect. An Easterlin-type interpretation seems more plausible. That is, real gains in income (or wealth, or consumption) may well result in only diminishing marginal utility, but relative gains which have the effect of raising one's status relative to others in the same society, are not subject to diminishing returns.

\subsection{Satisfaction with Material Standard of Living}

Table 3 now provides evidence for assessing the net effects of income, wealth consumption on satisfaction with material standard of living.

In all five countries wealth and income are both statistically significant at the 0.001 level in accounting for differences in satisfaction with standard of living. And in Hungary and Britain consumption too is significant at this level. Together with standard controls, the variance accounted for ranges from 13.0 per cent for Hungary to 22.3 per cent for The Netherlands. Not surprisingly this is considerably more variance than was accounted for in life satisfaction. 
Table 3

Impact of Wealth, Income and Consumption on Standard of Living Satisfaction (0-100):

OLS Regressions

\begin{tabular}{|c|c|c|c|c|c|}
\hline \multirow[t]{2}{*}{ Explanatory variables } & Australia & Britain & Germany & Hungary & Netherlands \\
\hline & Beta & Beta & Beta & Beta & Beta \\
\hline $\begin{array}{l}\text { Equivalised income } \\
\text { / } 1000\end{array}$ & $.13 .11^{* * *}$ & $.68 .20 * * *$ & $.02 .21^{* * *}$ & $.07 .10^{* * *}$ & $.16 \quad .17^{* * *}$ \\
\hline Net worth (ln) & $2.40 .19 * * *$ & $1.17 .13^{* * *}$ & $.09 .18^{* * *}$ & $.51 .10^{* * *}$ & $1.37 .23^{* * *}$ \\
\hline $\begin{array}{l}\text { Equivalised } \\
\text { consumption / } 1000\end{array}$ & na & $.94 .07^{* * *}$ & na & $.20 .14^{* * *}$ & na \\
\hline $\operatorname{Sex}(f=1, m=0)$ & $1.31 * * *$ & $1.39 * * *$ & $.13^{* * *}$ & $-.49^{\mathrm{ns}}$ & $.82 * * *$ \\
\hline Age & $-1.27 * * *$ & $-1.20 * * *$ & $-.08 * * *$ & $-1.63 * * *$ & $-.64 * * *$ \\
\hline $\mathrm{Age}^{2} / 10$ & $.16^{* * *}$ & $.14^{* * *}$ & $.01 * * *$ & $.15^{* * *}$ & $.07 * * *$ \\
\hline Partnered (1-0) & $3.97 * * *$ & $3.42 * * *$ & $.37 * * *$ & $3.75 * * *$ & $4.18 * * *$ \\
\hline Education (years) & $.53 * * *$ & $.15^{* * *}$ & $.02 * * *$ & $.12^{\mathrm{ns}}$ & $.88 * * *$ \\
\hline Working (1-0) & $4.67 * * *$ & $.65^{\mathrm{ns}}$ & $.03^{\mathrm{ns}}$ & $-1.50^{\mathrm{ns}}$ & $7.74 * * *$ \\
\hline Unemployed (1-0) & $-12.02 * * *$ & $-10.71 * * *$ & $-1.29 * * *$ & $-6.15 * * *$ & $-5.08 * *$ \\
\hline Bad health (1-0) & $-5.49 * * *$ & $-9.71 * * *$ & $-.01 * * *$ & $-1.09 * *$ & $-5.54 * * *$ \\
\hline Constant & $36.67 * * *$ & $58.45 * * *$ & $5.65 * * *$ & $66.42 * * *$ & $55.91 * * *$ \\
\hline $\mathrm{R}^{2}$ & $18.0 \%$ & $15.5 \%$ & $17.4 \%$ & $13.0 \%$ & $22.3 \%$ \\
\hline $\mathrm{N}$ & 11755 & 14101 & 9431 & 3055 & 5280 \\
\hline
\end{tabular}

Notes:

1. $* * *$ significant at 0.001 level; ** significant at 0.01 ; $*$ significant at 0.05 ; ns $=$ not significant.

2. Reference variable for employment status: 'not in the labour force'.

3. Equivalised incomes and consumption were divided by 1000 for all countries except Hungary, where the division was by 10000 . 
The evidence about the relative importance of wealth, income and consumption is somewhat distorted by the fact that in three countries - Britain, Germany and The Netherlands - the dependent variable is a measure of satisfaction with household income (not standard of living or financial situation), and thus provides a linguistic bias towards finding that income is more important than the other two measures. Even so, wealth appears to have about the same impact as income in all countries except perhaps Britain, and rather more in Australia and The Netherlands.

We now undertake the same exercise with standard of living as with life satisfaction, estimating the impact of upward mobility from the $25^{\text {th }}$ to the $75^{\text {th }}$ percentiles of wealth, income and consumption. In Hungary the gain in satisfaction would be 6.0 percentiles, 1.0 due to wealth, 1.7 due to income and 3.3 due to a gain in consumption. In Britain there would be a gain of 10.6 percentiles in satisfaction with standard of living; 3.6 percentiles due to a wealth increase, 5.6 to income and 2.4 to consumption.

\subsection{Longitudinal Analysis}

The results presented so far have been based on static analysis. An obvious way to extend and strengthen results is to undertake longitudinal analyses of the effects of changes in economic well-being on changes in satisfaction. We now do this for four of the five countries, omitting Australia for which only two years of data are available, thus making more powerful methods of longitudinal analysis inapplicable.

It was mentioned earlier that psychologists who have studied life satisfaction and domain satisfactions (including income and standard of living) have generally found that apparently major events and changes in people's lives often seem to have weak and even statistically non-significant effects on satisfaction levels. The usual explanation involves invoking adaptation theory - the hedonic treadmill idea that people rapidly adapt to new circumstances by changing their expectations for the future, so that their satisfaction levels, having perhaps risen or fallen for a brief time, soon revert to previous baseline levels.

There is no reason to doubt that some adaptation occurs in response to all or most life events and changes. However, adaptation is not always rapid and not always complete. It has been shown that parents who have lost a child killed in an accident never get back to their previous baseline level of happiness (Wortman and Silver, 1987). Somewhat similarly, it also appears 
that repeated spells of unemployment have a 'scarring' effect and permanently lower life satisfaction (Clark et al, 2004).

Researchers who have looked at the impact of changes in income on life satisfaction or income satisfaction have found very weak relationships and have routinely attributed this to adaptation (for a review see Diener and Biswas-Diener, 2002 and recall Brickman et al. 1978 who showed that big lottery wins had statistically non-significant on happiness). ${ }^{15}$ However, it is worth reassessing this conclusion for several reasons. First, inclusion of data on wealth and consumption, as well as income, may make a difference. Second, previous research has generally relied on just two or three years of evidence about income change, not long running panel data. Change has often been measured by first difference scores, which are notoriously subject to measurement error. With longer term panel data, we can make use of more powerful panel regression models. Third, as a matter of logic it is hard to see why the static results given earlier would not translate into similar longitudinal results. If the main reason that people who have higher income levels are satisfied with lives is that they enjoy being relatively better off than their fellow citizens, then why would not income changes which improve their relative position have the same effect? Static data and change data really ought to show the same thing.

The longitudinal results given for Germany, Britain, The Netherlands and Hungary in Table 4 are all based on using satisfaction with standard of living as the dependent variable, ${ }^{16}$ and are all fixed effects (within column) models analysed with the STATA panel regression software. We preferred a fixed effects model to random effects primarily because it seemed likely that there would be unobserved fixed effects (e.g. personality traits and effects due to inherited wealth) which would probably be correlated with variables on the RHS. It should also be noted that the assumptions behind a random effects model were rejected by the Hausman test. We recognise that the decision to use a fixed effects model would be disputed by some specialists who believe that it is generally preferable to use random effects in analyzing household panels (e.g., Baltagi, 1995). It may be noted that, had a random effects model been used, all coefficients in Table 4 would be larger. So the decision to use fixed effects was, in a sense, a conservative one. Results are given for the latest decade available (but under 10

\footnotetext{
${ }^{15}$ An exception is Frijters et al. (2004).

${ }^{16}$ The life satisfaction results showed a similar pattern in that the coefficients derived from fixed effects models were much larger than from first difference equations. As expected, all coefficients were lower than for satisfaction with standard of living (compare Tables 2 and 3).
} 
years of data were available for Britain on consumption, and the Hungarian panel ran from 1992-97).

The results for all four countries can be read as showing that changes in economic well-being have statistically significant effects on changes in satisfaction with standard of living. It is notoriously hard to get strong or even significant results with fixed effects models, and the coefficients (Bs) in Table 4 are certainly not large. A fair conclusion might be that, while adaptation is doubtless occurring, it does not swamp everything else. The subjective effects of changing financial circumstances are clearly detectable.

\section{Table 4}

Impact of Changes in Income, Consumption and Wealth on Standard of Living Satisfaction (0-100): Fixed Effects Models

\begin{tabular}{lcccc}
\hline Explanatory variables & $\begin{array}{c}\text { Germany } \\
1993-2002\end{array}$ & $\begin{array}{c}\text { Britain } \\
1997-2000\end{array}$ & $\begin{array}{c}\text { Netherlands } \\
1988-97\end{array}$ & $\begin{array}{c}\text { Hungary } \\
1992-97\end{array}$ \\
& $B$ & $B$ & $B$ & $B$ \\
\hline Equivalised income / 1000 & $.14^{* * *}$ & $.08^{* * *}$ & $.04^{* * *}$ & $.02^{* *}$ \\
$\begin{array}{l}\text { Equivalised consumption / } \\
\mathbf{1 0 0 0}\end{array}$ & na & $2.00^{* * *}$ & na & $-.09^{* * *}$ \\
Net worth (ln) & na & Na & $.39 * * *$ & $.20^{* * *}$ \\
Constant & $58.75^{* * *}$ & $51.65^{* * *}$ & $59.90^{* * *}$ & $45.38^{* * *}$ \\
$\mathrm{~N}$ & 28687 & 16433 & 16094 & 6124 \\
\hline
\end{tabular}

Notes:

1. ${ }^{* * *}$ significant at 0.001 level; $* *$ significant at 0.01 ; $*$ significant at 0.05 ; ns $=$ not significant.

2. Equivalised incomes and consumption were divided by 1000 for all countries except Hungary, where the division was by 10000 .

Let's take each country in turn. For Germany we only have evidence relating to the effects of equivalent income changes on household income satisfaction. A fixed effects coefficient of 0.14 ( $\mathrm{t}=35.76, \mathrm{p}=.001$ ) can be read as indicating that a gain or loss of DM 1000 of income results in a change of 0.14 percentiles on the satisfaction scale. This may not seem much, but 
note that a comparable first difference equation of the kind used in most previous research yielded an OLS regression coefficient for the effect of income change on income satisfaction in 2002-03 of $0.07(\mathrm{t}=5.23, \mathrm{p}=.001)$.

The Dutch evidence relates to both income and wealth (net worth). Changes in both these variables had significant if small effects on people's assessment of how well they were getting along on their household income.

For Britain we only have four years (1997-2000) for which data on both income and consumption were collected. Despite this short time period, which makes it less likely that a fixed effects model will yield statistically significant results, we find that both income changes and consumption changes were significant. Contrary to the evidence for Britain in Table 3, consumption changes seemed to matter more.

Finally, Hungary. The Hungarian panel is potentially the most useful one for this exercise, since data were collected on wealth, income and consumption every year in 1992-97. However, the results contain an anomaly. Whereas changes in wealth and income were significantly and positively related to changes in satisfaction with standard of living, the effects of changes in consumption were significant but negative. Even post hoc it is hard to think of a reasonable explanation for this result!

\section{Alternative specification}

The main alternative specification tried was based on the idea that the dependent variable should be current satisfaction, not change in satisfaction. That is, one might hypothesise that a person's current satisfaction would be higher or lower depending on recent changes in material circumstances. In practice, however, equations on these lines yielded weaker relationships than shown in Table 4. This result too can be interpreted in an Easterlin sense; that is, changes in satisfaction, like levels of satisfaction, are driven primarily by one's own material well-being relative to others in society. Upward changes in one's relative position generates increased satisfaction, while downward changes generates dissatisfaction. 


\section{Discussion}

First some measurement issues. The results in this paper, if confirmed, suggest that the managers of household panels should try to include measures of both wealth and consumption, as well as income, on an annual basis. Neither measure need take up an inordinate amount of interviewing time and money. The GSOEP experience in 2002 showed that wealth can be measured with a page of questions, and Browning et al's (2003) calculations show that, for some countries at least, household consumption on non-durables can be adequately inferred from responses to just two questions about food expenditure.

Other objections to not including wealth and consumption carry little weight. One set of objections rests on an assumption that wealth, and perhaps consumption, are fairly stable over time and so do not need to be measured every year. Nothing in the data for Britain, The Netherlands and Hungary, used in this paper, gives much support to this assumption. In The Netherlands household wealth was somewhat more stable than income, although not much. In Hungary the reverse was true. One might note that wealth mainly consists of housing, shares and pension entitlements. Housing and shares fluctuate widely in value, and so do pension entitlements if (as in many countries) they are held substantially in shares. So there is really no sound reason to assume that wealth or net worth are especially stable. The same is true of consumption. In both Britain and Hungary consumption covaried with income over time (of course), but while in Britain it was more stable than income, in Hungary it was less so.

A final possible objection is that it appears arithmetically unnecessary to measure all three of wealth, income and consumption every year. If one can accurately measure two of them, then changes in the third can be calculated. In practice, however, this does not work. Measurement errors in all three items are sufficiently large that no such inferences are valid. It is preferable to measure all three separately and, for some purposes, treat them as multiple indicators of the underlying concept of economic well-being or material standard of living.

Now issues relating to psychological and economic theory. Arguably, our results have implications both for the psychology literature on happiness and for welfare economics. The implications for psychology are obvious and just involve a modified understanding of what matters to happiness or SWB. The implications for economics are more subtle. If the 'revealed preferences' approach survives the challenges it currently faces, then research on happiness will presumably remain on the fringe of economics. If, on the other hand, it comes to be accepted by increasing numbers of economists that gains in utility cannot be validly 
inferred from gains in consumption and leisure, then issues will arise about the need for direct measurement of utility/happiness. It will then be comforting to know that household living standards - and therefore, by inference, national economic growth - matter significantly to happiness.

A final editorial remark. Nothing in this paper should be read as indicating that psychologists have got it wrong in claiming that personality and personal relationships matter a lot more to happiness than money and material well-being. Nor do we necessarily deny the claim by some psychologists that giving top priority to material gain is toxic to happiness (Nickerson et al., 2003). All we claim is that by including wealth and consumption, as well as income, on the right hand side of equations, we have shown that money matters more to happiness than previously believed. 


\section{References}

Andrews, F.M. and Withey, S.B. (1976). Social Indicators of Well-being: Americans' Perceptions of Quality of Life. New York: Plenum Press.

Argyle, M. (1987). The Psychology of Happiness. London: Routledge.

Baltagi, B.H. (1995). Econometric Analysis of Panel Data. New York: Wiley.

Barrett, G.F., Crossley, T.F. and Worswick, C. (2000). Consumption and income inequality in Australia. The Economic Record, 76, 116-38.

Brickman, P., Coates, D.D. and Janoff-Bulman, R. (1978). Lottery winners and accident victims: is happiness relative? Journal of Personality and Social Psychology, 36, 917-27.

Bradburn, N.M. (1969). The Structure of Psychological Well-Being. Chicago: Aldine.

Browning, M. , Crossley, T.F. and Weber, G. (2003). Asking consumption questions in general purpose surveys. The Economic Journal, 113, 540-567.

Buhmann, B., Rainwater, L. Schmaus, G. and Smeeding, T.N. (1988). Equivalence scales, well-being, inequality and poverty: sensitivity estimates across ten countries, using the Luxembourg Income Study (LIS) database. The Review of Income and Wealth, 34, 115-42.

Campbell, A., Converse, P.E. and Rodgers, W.L. (1976). The Quality of American Life: Perceptions, Evaluations, and Satisfactions. New York: Russell Sage Foundation.

Clark, A.E., Georgellis, Y., Lucas, R.E. and Diener, E. (2004). Unemployment alters the setpoint for life satisfaction. Psychological Science, forthcoming.

Coulter, F.A.E., Cowell, F.A. and Jenkins, S.P. (1992). Equivalence scale relativities and the extent of inequality and poverty. Economic Journal, 102, 1067-82.

Cutler, D and Katz, L. (1992). Rising inequality?' American Economic Review, 82, 546-51.

Diener, E. (1984). Subjective well-being. Psychological Bulletin, 95, 542-575.

Diener, E., Suh, E.M., Lucas, R.E. and Smith, H.L. (1999). Subjective well-being: Three decades of progress. Psychological Bulletin, 125, 276-302. 
Diener, E. and Biswas-Diener, R. (2002). Will money increase subjective well-being? A literature review and guide to needed research. Social Indicators Research, 57, 119-169.

Duesenberry, J.S. (1949). Income, saving and the theory of consumer behavior. Cambridge: Harvard University Press.

Easterlin, R.A. (1974). Does economic growth improve the human lot? Some empirical evidence. In P.A. David and M.W. Reder (eds), Nations and Households in Economic Growth: Essays in Honour of Moses Abramowitz. New York: Academic Press, 89-125.

Easterlin, R.A. (1995). Will raising the incomes of all increase the happiness of all? Journal of Economic Behavior and Organization, 27, 35-47.

Frank, RH (1985). The demand for unobservable and other nonpositional goods. American Economic Review, 75, 101-16.

Frey, B.S. and Stutzer, A. (2002). What can economists learn from happiness research? Journal of Economic Literature, 40, 402-435.

Frijters, P., Haisken-Denew, J.P. and Shields, M.A. (2004). Money does matter! Evidence from increasing real incomes and life satisfaction in East Germany following reunification. American Economic Review, forthcoming.

Goodin, R.E., Headey, B.W., Muffels, R. and Dirven, H-J. (1999). The Real Worlds of Welfare Capitalism. Cambridge: Cambridge University Press.

Headey, B.W. and Wearing A.J. (1989). Personality, life events and subjective well-being: toward a dynamic equilibrium model. Journal of Personality and Social Psychology, 57, 73139.

Headey, B.W. and Wearing, A.J. (1992). Understanding Happiness. Melbourne: Longman Cheshire.

Hollaender, H. (2001). On the validity of utility statements: standard theory versus Duesenberry’s. Journal of Economic Behavior and Organization, 45, 227-49.

Juster, T., Smith, J.P. and Stafford, F. (1999). The measurement and structure of household wealth. Labour Economics, 6, 253-276. 
Kahnemann D., Diener, E. and Schwarz, N. (1999). Well-Being: The Foundations of Hedonic Psychology. New York: Russell Sage Foundation.

Kapteyn, A., Kooreman, P. and Willemse, R. (1988). Some methodological issues in the implementation of subjective poverty definitions. Journal of Human Resources, 23, 222-42.

Mullis, R.J. (1992). Measures of economic well-being as predictors of psychological wellbeing. Social Indicators Research, 26, 119-135.

Nickerson, C., Schwarz, N., Diener, E., and Kahnemann, D. (2003). Zeroing in on the dark side of the American Dream: A closer look at the negative consequences of the goal for financial success. Psychological Science, 14, 531-36.

Oswald, A.J. (1997). Happiness and economic performance. Economic Journal, 107, 181531.

Samuelson, P.A. (1938). A note on the pure theory of consumer's behavior. Economica, 5, 61-71.

Slesnick, D.T. (1998). Empirical approaches to the measurement of welfare. Journal of Economic Literature, 36, 2108-65.

Van Praag, B.M.S. (1993). The relativity of the welfare concept. In M.C. Nussbaum and A Sen (eds), The Quality of Life. Oxford: Clarendon Press, 362-85.

Van Praag, B.M.S., Hagenaars, A.J.M. and van Weeren, J. (1982). Poverty in Europe. The Review of Income and Wealth, 28, 345-59.

Veenhoven, R. (1984). Conditions of Happiness. Dordrecht: Reidel.

Wortman, C.B. and Silver, R.C. (1987). Coping with irrecoverable loss. In G.R. Vanderbos and B.K. Bryant (eds), Cataclysms, Crises, Catastrophes: Psychology in Action. Washington, D.C.: APA 


\section{Appendix}

Correlations: Life Satisfaction (LS) and Standard of Living Satisfaction (SLS) with Net Worth, Equivalised Income and Equivalised Consumption

\begin{tabular}{|c|c|c|c|c|c|c|c|c|c|c|}
\hline & \multicolumn{2}{|c|}{$\begin{array}{l}\text { Australia } \\
2002 \\
(\mathrm{~N}=12559)\end{array}$} & \multicolumn{2}{|c|}{$\begin{array}{c}\text { Germany } \\
2002 \\
(\mathrm{~N}=17785)\end{array}$} & \multicolumn{2}{|c|}{$\begin{array}{c}\text { Netherlands } \\
1997 \\
(\mathrm{~N}=4288)\end{array}$} & \multicolumn{2}{|c|}{$\begin{array}{c}\text { Britain } \\
2000 \\
(\mathrm{~N}=14439)\end{array}$} & \multicolumn{2}{|c|}{$\begin{array}{c}\text { Hungary } \\
1996 \\
(\mathrm{~N}=3061)\end{array}$} \\
\hline & LS & SLS & LS & SLS & LS & SLS & LS & SLS & LS & SLS \\
\hline Income & 0.07 & 0.19 & 0.17 & 0.30 & na & 0.29 & 0.11 & 0.29 & 0.20 & 0.20 \\
\hline Net worth & 0.14 & 0.30 & 0.19 & 0.30 & na & 0.30 & 0.13 & 0.22 & 0.14 & 0.14 \\
\hline Consumption & na & na & na & na & na & na & 0.06 & 0.17 & 0.22 & 0.23 \\
\hline
\end{tabular}

